\title{
ONE OF OPPORTUNITIES TO REDUCE STUDENT DROPOUTS
}

\author{
Aivars Aboltins, Svetlana Atslega, Natalija Sergejeva, Liene Strupule \\ Latvia University of Life Sciences and Technologies, Latvia \\ aivars.aboltins@inbox.lv, natalija.sergejeva@1lu.lv
}

\begin{abstract}
It is a well known fact that a large number of students leave their studies already during the first year. Some of them understand that it is not the right specialty for them; some students mention their inability to acquire definite study subjects, for instance, the course of higher mathematics, as the reason for leaving studies. It should be noted that often the problems do not arise due to the acquisition of higher mathematics, but due to the lack in the basic knowledge in mathematics. The results of testing the first year students in the knowledge of mathematics of the elementary school level show that about $60 \%$ of them have unsatisfactory knowledge. These are the students, who potentially will not be able to acquire the course in higher mathematics of full value. The problem arises how to help them, as they may become (or already are) good specialists in their branch of specialty. This year, in cooperation of the teachers of the Department of Higher Mathematics and the Faculty of Food Engineering, a study course "Elementary Mathematics" (1CP) was organised. The students, whose test results were unsatisfactory, were especially invited to attend this course. Finishing the course, the students were tested once more. The results of this test showed that the students' knowledge in elementary mathematics has essentially improved. The offered solution is not universal, as it helps only fill the gaps in knowledge, but it cannot help acquire all knowledge and skills of elementary mathematics within several hours.
\end{abstract}

Keywords: mathematics education, repeat, course, teaching mathematics.

\section{Introduction}

During the recent years the number of students at higher schools and colleges in Latvia has become smaller. According to the data of the Central Statistical Bureau the total number of students during the last 10 years (from 2009 to 2018) has reduced by 32212 students, and this number has been declining with every year [1]. Also the proportional number of students, who obtain the qualification, compared to the number of the students, who have been enrolled in the corresponding year, is reducing and within the last five years it is in the range 50-60\% (for comparison, for instance, in 2010 it was $86 \%$, which is the best result during the last ten years). The reduction of the total number of students can be explained by the demographical situation in Latvia, as the total number of inhabitants during this period has reduced by more than 228 thousands. The reduction of the proportional number of the students, who have obtained the qualification, can be explained by the large drop-out of the students during the studies, especially in the first year.

Often the students who leave the studies mention their inability to acquire definite study subjects, for instance, the course of higher mathematics, as the reason for leaving. Also the teachers of higher mathematics recognise the insufficient level of knowledge in basic mathematics that is necessary for the studies. This problem exists also in other countries, and it has been recognised during many tens of years. For instance, researches in the USA show that only about a half of those who enter higher schools graduate with a bachelor's degree, the others drop out [2]. The same author notes that the foundation of mathematics is laid in the early years of elementary school. To succeed in college, this foundation must be solid.

In the European Reference Framework of Key Competences for Lifelong Learning one of the competences listed is mathematical competence, and also basic competences in science and technology. Mathematics is an instrument; mathematical reasoning is essential for a wide range of daily activities, tasks and professions. It is also a key to academic areas of study, such as sociology, psychology, history, geography, economics or politics. Together with literacy, a basic level of mathematical reasoning is a basic skill that is a pre-requisite for the development of other key competences [3].

There are also views that the role of mathematics will decrease [4]. This is certainly an important point to consider. However, while computers may be able to solve arithmetic problems, they cannot formulate real life problems in terms of arithmetic or algebra, and they cannot interpret what the results mean for the initial problem. Another approach might be to shift the focus towards mathematical computing, allowing for much more realistic problems. Finally, it may be worth noting that many of the jobs that advance technology and society as a whole - from computer programming 
to electrical and mechanical engineering, scientific research, company management or finance require a significant amount of mathematics. Thus, it is clear why the government and industry are very concerned by the fact that the number of students with an "advanced understanding" of mathematics is declining [5].

Today in Latvia finishing school, the school leavers have to pass three compulsory centralised examinations. Till 2011/2012 school year there was a regulation that the examination is not passed, if the total assessment of the examination work is zero per cent (and with this, the school leaver cannot obtain the education certifying document). From 2012 it is established that assessment is obtained, if the assessment of the examination work is not less than five per cent.

Already for ten years (from 2009) the centralised examination in mathematics is compulsory for secondary school leavers. One of the aims of its introduction has been to underline the importance of this subject and motivate its acquisition. Table 1 shows some results of the centralised examination during the recent ten years [6], indicating the total number of school leavers, who have taken the examination, who have not passed it, and the average result in the corresponding year. It can be seen that the total number of those, who have taken the examination, during ten years has reduced for almost a half (by $45 \%$, comparing 2009 and 2018). It can be explained by the demographic situation in Latvia.

Thinking about the future, this is a reason to consider the number of higher schools and students in the country. Even more alarming is the fact that, irrespective to the low requirements that allow to pass this examination, in recent years the number of school leavers, who do not pass it, increases. It means they do not achieve even $5 \%$ in the total assessment. And the average result of the examination is also declining.

Table 1

Results of centralised examination in mathematics in last ten years in Latvia

\begin{tabular}{|c|c|c|c|}
\hline Study year & $\begin{array}{c}\text { Average result of } \\
\text { examination, \% }\end{array}$ & $\begin{array}{c}\text { Total number of } \\
\text { school leavers taking } \\
\text { the examination }\end{array}$ & $\begin{array}{c}\text { Number of failing the } \\
\text { examination }\end{array}$ \\
\hline $2008 / 2009$ & 37.1 & 25443 & 3 \\
\hline $2009 / 2010$ & 37.3 & 24343 & 1 \\
\hline $2010 / 2011$ & 35.6 & 23823 & 0 \\
\hline $2011 / 2012$ & 42.9 & 20498 & 89 \\
\hline $2012 / 2013$ & 37.3 & 17777 & 132 \\
\hline $2013 / 2014$ & 43.3 & 16430 & 62 \\
\hline $2014 / 2015$ & 43.6 & 14616 & 119 \\
\hline $2015 / 2016$ & 36.2 & 14185 & 219 \\
\hline $2016 / 2017$ & 34.9 & 13335 & 223 \\
\hline $2017 / 2018$ & 34.6 & 13899 & \\
\hline
\end{tabular}

As there is the compulsory centralised examination in mathematics at secondary school, entrance examinations in mathematics at higher schools are not organised. It means that students with very different levels of knowledge in mathematics enter higher schools. The experience of the authors of the article shows that in the groups of the future engineers the results of the centralized examination in mathematics are in the range from $5 \%$ to $98 \%$. It means that among the students there are such students who need help, first of all, a repetition course in basic mathematics. At the same time, there are also students who need to have very high motivation and additional work to be able to study at the university.

Wherewith, the repetition course in basic mathematics could be offered as additional sessions without $\mathrm{CP}$ for its acquisition. The experience of the authors shows that it is not the right solution. The number of students with a low level in the knowledge of mathematics, but highly motivated to attend extra-curriculum sessions, is small. So, it is a better solution to offer a small course from the point of view of $\mathrm{CP}$ that is compulsory for the whole group of students. In this case writing the final work and taking the test are obligatory. 


\section{Materials and methods}

The present research is a continuation of the research last year, which is described in [7]. In September 2018, starting the studies, the students were offered a test including only mathematics basic knowledge and basic skills, which are acquired already at primary school. This choice can be explained by the fact, according to the authors, that more successful acquisition of the course of higher mathematics depends exactly on the knowledge of basic knowledge in mathematics. The scope of mathematics that is necessary for representatives of various professions is different, but the knowledge of basic mathematics acquired at school should be equal in order to be able to make a career in different spheres.

In total, at the beginning of the 2018/2019 study year, 209 LLU students participated in the research: 80 second year students (51 students with $10 \mathrm{CP}$ and 29 with $11 \mathrm{CP}$ course of mathematics), 28 first year students with $5 \mathrm{CP}$ course of mathematics, 63 first year students with $10 \mathrm{CP}$ course of mathematics and 38 first year students with $11 \mathrm{CP}$ course of mathematics.

The obtained results were investigated in different aspects: 1) the level was stated of the first year students, who started their studies in the current year, 2) achievements of the students of the same specialty in the previous year (when they were first year students) and in the current year (second year students) were compared, 3) achievements of the students before and after repetition of the elementary mathematics course were compared.

\section{Results and discussion}

Summarising the research results, it can be seen that the average first year students' results even do not reach $40 \%$ of the maximally possible number of points (see Fig. 1). Assessment of the second year students is a little higher: $41 \%$ of students of one specialty; and the average assessment of students of other specialties is $53 \%$.

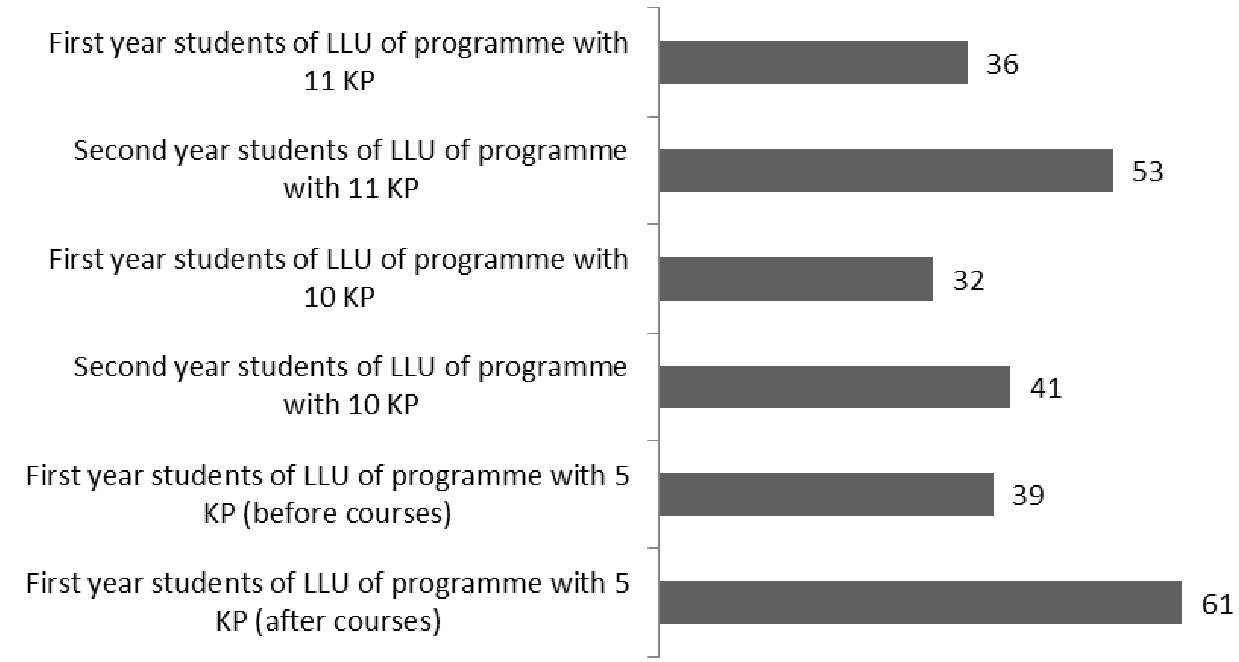

Fig. 1. Average test results in different groups of students starting study year 2018/2019

The results achieved by the first year students with $11 \mathrm{CP}$ course of mathematics can be seen in Fig. 2. The average result for these students is $36 \%$ of the maximally possible number of points. High results (more than $80 \%$ ) were achieved by $8 \%$ of the students, but less than $40 \%$ were achieved by $63 \%$ of the students.

The future engineers with $10 \mathrm{CP}$ mathematics course had even worse results. The average result is only $32 \% .75 \%$ of the students achieved $40 \%$, only $5 \%$ of the students of this group reached $80 \%$. Besides, for one third of the students the result is in the range 10-20\%.

The results of the students with $5 \mathrm{CP}$ mathematics course are shown in Fig. 4. The results of these students were in average $39 \%, 57 \%$ of the students from this group reached $40 \%$, in turn, the result higher than $80 \%$ was reached only by $7 \%$ of the total number of students. 


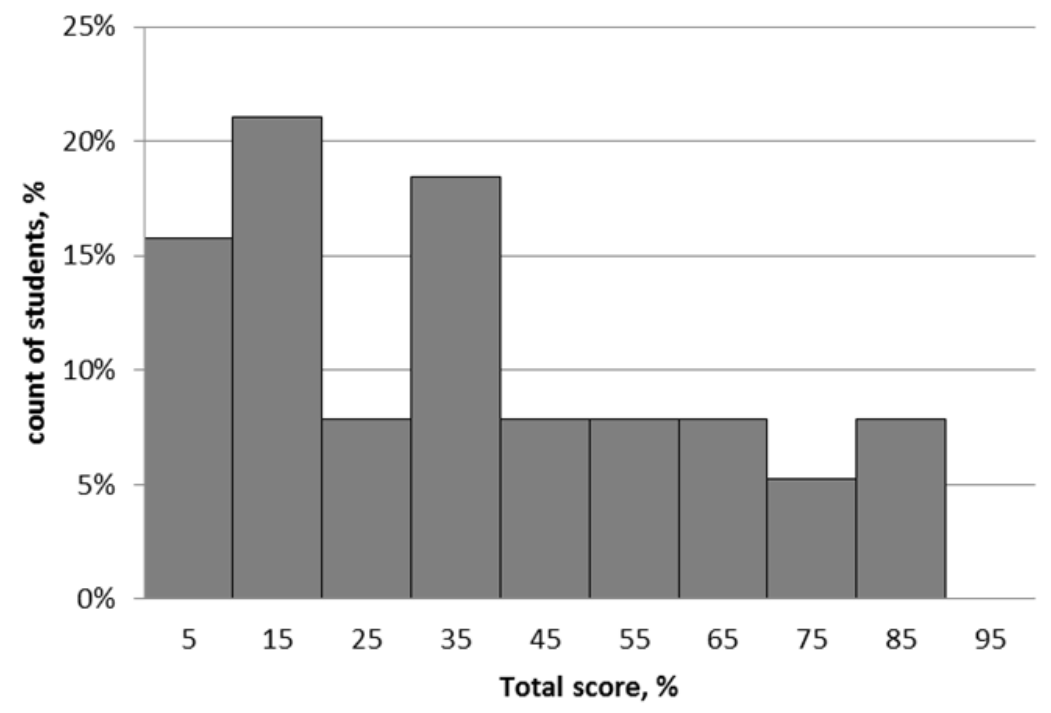

Fig. 2. Test results of first year students with $11 \mathrm{CP}$ mathematics course

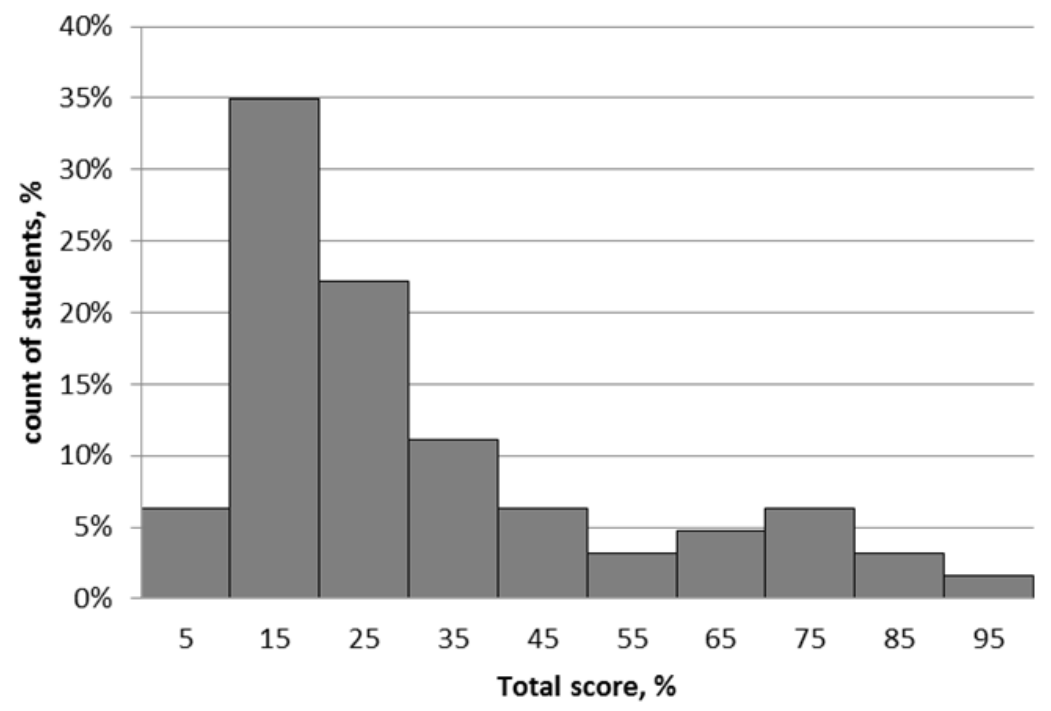

Fig. 3. Test results of first year students with $10 \mathrm{CP}$ mathematics course

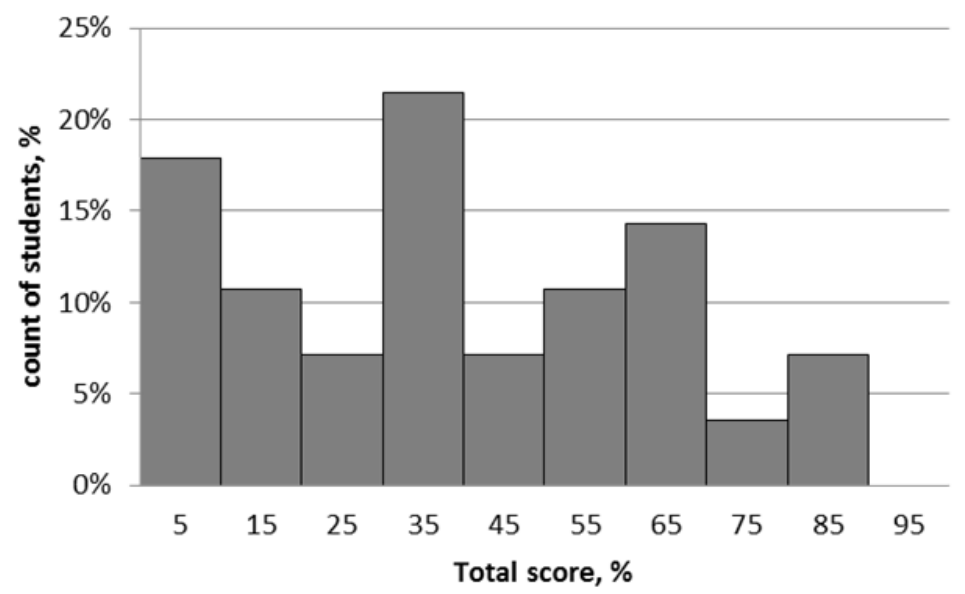

Fig. 4. Test results of first year students with $5 \mathrm{CP}$ mathematics course

As it was mentioned above, the authors could compare the results of the same group of the students in the first year and starting to study in the second year. Only the students who participated in the test in both years were selected and the results can be seen in Fig. 5. Starting their studies at the 
university, the average result of this group of students was $47 \%$ (with standard deviation 7.9), but starting to study in the second year it was $56 \%$ (with standard deviation 8.1). In both years 26 students were tested, 19 of them showed a better result, 4 showed a worse result than in the previous year, but the incline/decline of the results in total is not essential (except two students, whose test results improved about two times, from $39 \%$ to $76 \%$ and from $39 \%$ to $86 \%$ ).

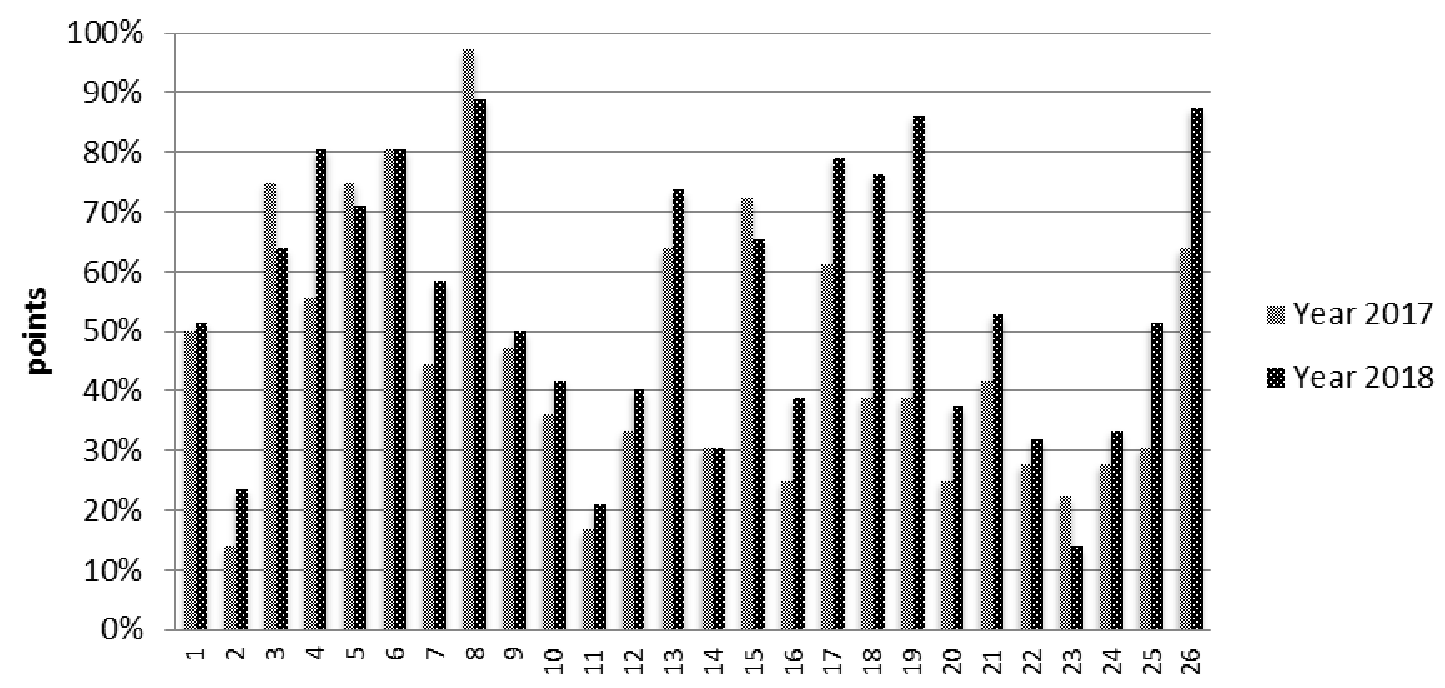

Fig. 5. Comparison of results of students with $11 \mathrm{CP}$ mathematics course in two years

Based on several years' long experience, by support of the Faculty of Food Engineering management this year a course was developed (1CP) for repetition of basic mathematics. It is not possible to include the bases of elementary mathematics in the material of studies during the first semester, as the number of credit points allowed for mathematics courses has been reduced.

The students for this course were selected according to the test results, the test was compulsory for all students of the corresponding group. To get a credit point the students had to write the final test also, attendance of sessions was not compulsory.

Also the results of the centralised examination could serve as a criterion for the selection of students, but in the authors' opinion, the results of the test is a better solution. It can be explained by the fact that during the recent years among students a tendency can be observed to start studies not straight after finishing the secondary school, bet a few years later. In this situation the results of the centralised examination do not clearly characterise the mathematical readiness of students for studies.

The sessions took place for four weeks with four sessions per week. At the end the students performed the test similar to the previous one in its structure. It allowed to compare the levels of acquisition of definite topics before and after the elementary mathematics course. Only the students who performed both tests were selected for this purpose. Improvement in the results was observed in all tasks (see Fig. 6). The authors, being teachers of higher mathematics, are especially happy to observe the improved knowledge and skills of the students in the results of Task 4 (exponentiation in negative power), Task 6 (simplification of algebraic fractions), Task 11 (skill to derive value from formula) and Task 12 (solution of quadratic equation). Unfortunately, working with these students later, it was observed that they did not apply the knowledge acquired in the course in their studies afterwards.

"Intensive interventions should be put in place during the course of first-year engineering programmes to ensure that students' core mathematical skills are robust " [8].

In the authors' opinion, such course should be taught by the teacher, who teaches the course of higher mathematics in the initial stage at the university. It allows to link the course of elementary mathematics and the course of higher mathematics more successfully and to motivate the students for more intensive independent work. 

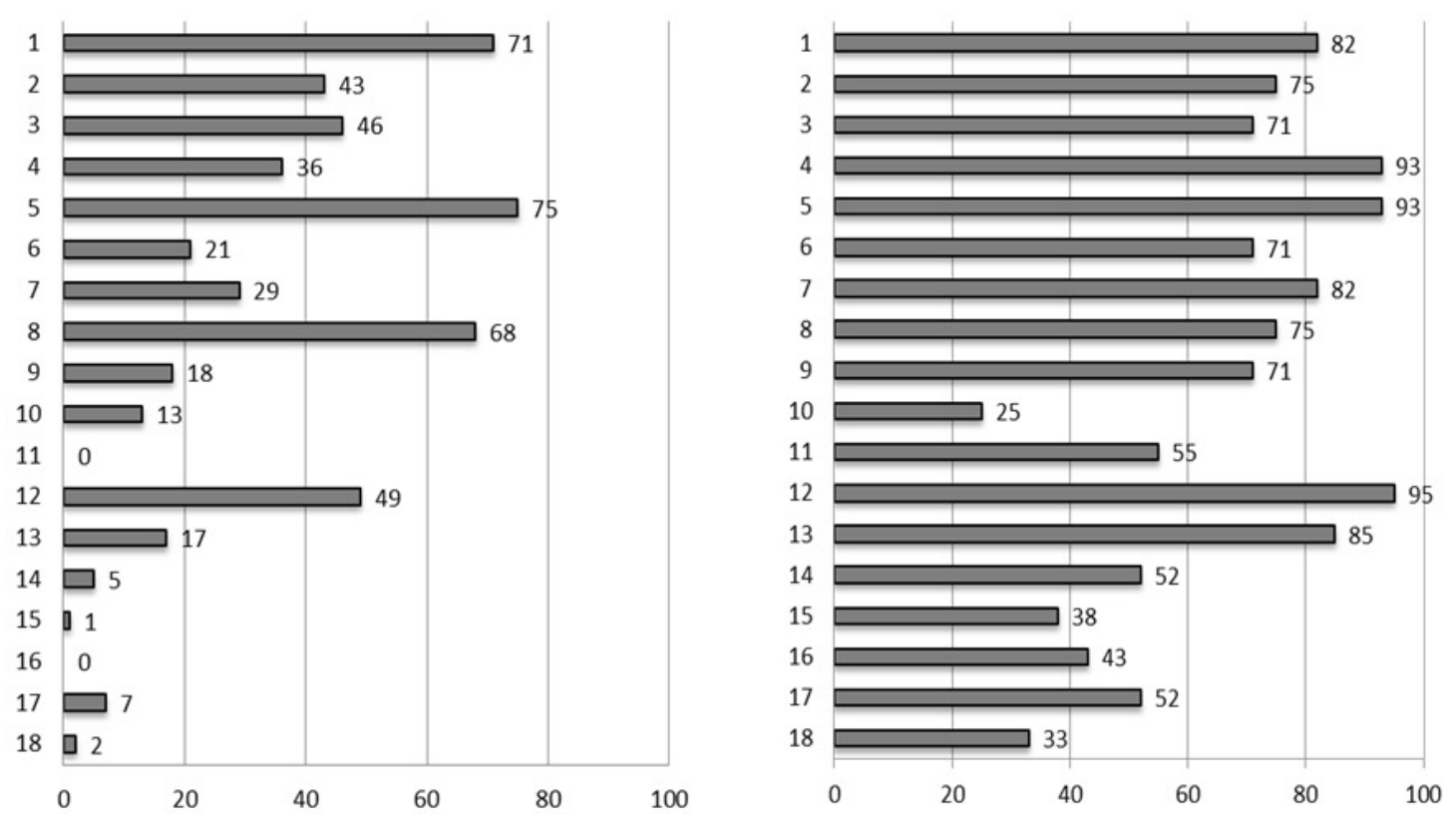

Fig. 6. Comparison of student performance before and after repetition course (performance of every task in per cent)

\section{Conclusions}

1. Students with different levels of basic knowledge in mathematics enter higher schools; it causes difficulties in acquisition of the current material in studies.

2. Teaching mathematics at primary school, more attention should be paid to application of mathematics to arouse interest in learning it. It should be shown that computers are only auxiliary means in solving real tasks.

3. Mathematics repetition course with assessment should be obligatory included in the curricula for the first year students. Such course should be intensive, but short, as acquisition of this course faster will help in more successful acquisition of the basic study courses. The repetition course should be taught by the teachers, who are teaching also the subsequent course of higher mathematics.

\section{References}

[1] Centrālā statistikas pārvalde. (Central Statistical Bureau) [online] [05.04.2019.] Available at: http://www.csb.gov.lv/

[2] Wilson W. S. Elementary School Mathematics Priorities. AASA Journal of Scholarship \& Practice, 6 (1), 2009, pp. 40-49.

[3] Council Recommendation on Key Competences for Lifelong Learning, 2018. [online] [01.04.2019] Available at: https://ec.europa.eu/education/education-in-the-eu/councilrecommendation-on-key-competences-for-lifelong-learning_en

[4] Is Algebra Necessary? Andrew Hacker, 28 July 2012 [online] [01.04.2019] Available at: www.nytimes.com/2012/07/29/opinion/sunday/is-algebra-necessary.html

[5] Teenagers 'worse at math than in 1970s', figures show. Graeme Paton, 21 Jun 2012. [online] [01.04.2019] Available at: telegraph.co.uk/education/educationnews/9344505/Teenagers-worseat-maths-than-in-1970s-figures-show.html

[6] Valsts izglitīibas satura centrs. (National Centre for Education of the Republic of Latvia) [online] [01.04.2019] Available at: https://visc.gov.lv/

[7] Sergejeva N., Aboltins A., Strupule L., Aboltina B. Mathematical knowledge in elementary school and for future engineers. 17th International scientific conference "Engineering for rural development": Proceedings, Jelgava, Latvia, May 23-25, 2018, pp. 1166-1172.

[8] Nahari N. Mathematical skills and attitudes of first year engineering students, Master theses, Dublin City University 2014, 110 p. [online] [01.04.2019] Available at: http://doras. dcu.ie/20200/1/ThesisNoha.pdf 